\title{
Applications status and prospects of remote sensing technology in geographic national conditions monitoring
}

\author{
Hongquan Xie \\ School of Geodesy \& Geomatics Engineering \\ Huaihai Institute of Technology \\ Lianyungang, P.R.China \\ xiehongquan@163.com
}

\begin{abstract}
Remote sensing technology has been widely applied in many fields, in recent years with the advance of geographical national conditions monitoring pilot, remote sensing images has become an important part in geographic national conditions monitoring system, is an important data acquisition means. In this paper, the domestic and foreign geography national conditions monitoring work progress were briefly introduced, and application field of geographic national conditions and monitoring was elaborated, mainly including resource environmental monitoring, disaster dynamic monitoring, land use dynamic monitoring, monitoring of urban change and construction management, monitoring of agriculture, forestry and water conservancy. Finally, future trends were predicted based on the analysis of existent problems to remote sensing technology in geographic national conditions monitoring. We believe that remote sensing technology will play an important role to carry out a comprehensive geographic national conditions monitoring.
\end{abstract}

Index Terms - remote sensing, geographic national conditions monitoring, applications field, existent problems, prospects.

\section{INTRODUCTION}

Geographic national conditions monitoring, comprehensive utilization of global navigation satellite systems, aerospace remote sensing technology, geographic information system technology and other modern mapping technology, comprehensive surveying and mapping results during the file on terrain, river systems, wetlands, glaciers, deserts, surface morphology, surface coverage, roads, towns, and other elements of a dynamic and the quantitative space of monitoring, and statistical analysis of the amount of changes, changes in the frequency, distribution characteristics, geographical differences, trends, and form a space to reflect all kinds of resources, environment, ecology, economic factors distribution and development of the variation of the monitoring data, maps, graphics and reports, from the point of view of the geospatial objective, comprehensive display of national conditions and strength [1]. The core technology of geographic national conditions monitoring system by relying on remote sensing, satellite navigation and positioning, geographic information system technology, integrated communications, cloud computing, Internet of Things technologies such as data mining and spatial statistics[2]. Remote sensing technology and geographic national conditions monitoring is a very close relationship, and has become an important geographical national conditions monitoring data acquisition means[3].

\section{APPLICATIONS STATUS OF REMOTE SENSING TECHNOLOGY IN GEOGRAPHIC NATIONAL CONDITIONS MONITORING}

\section{A.Major Progress Abroad}

In recent years, developed countries around the geographic national conditions monitoring have done many projects, mostly including: Britainic global drought monitoring network, the European released global soil overlay of the world's highest resolution, the European Union and other organizations expanded geographic monitoring of food crisis area, the EU's global environmental and security monitoring plan, the United States National Ecological Observatory Network, the Asia-Pacific Environmental Innovation Strategy Project Environmental monitoring subprojects [4].

\section{B.Major Domestic Progress}

Over the years, Chinese mapping departments in geographic national conditions, monitoring and analysis of the situation in the province, a number of attempts. But mainly exploratory work, has not yet formed the scale, the formation of the system. At the national level, in February 1992, the State Bureau of Surveying and Mapping, jointly with the Secretariat of the General Office of the State Council Development and construction of the State Council national conditions and geographic information systems. At the local level, the Geographic Information Center of Chongqing, Zhejiang, Heilongjiang Province, Geographical Information Bureau of Surveying and Mapping, Surveying and Mapping Bureau of Gansu Province, Qinghai Province, relevant research projects. 


\section{APPLICATIONS FIELD OF GEOGRAPHIC NATIONAL CONDITIONS MONITORING}

In recent years, remote sensing technology has been applied to the monitoring of multiple areas of geographic national conditions[5], combined with the application of the case on the geography national conditions monitoring applications described below:

(1) Resource Ecological Environment Monitoring. In June 2010, the completion of the construction project of the Qinghai Basic Geographic Information Center "Qinghai Lake area of remote sensing dynamic monitoring of geographic information systems. The system uses high-resolution remote sensing satellite images, high-precision GPS every year in May (dry season), September (wet period) in two phases of the Qinghai Lake area monitoring, and public regularly monitoring the outcome of the whole society. Currently, the system has been completed 70 years history of the Qinghai Lake area measurements from 2000, 2005, 2008, and June 2010, the Qinghai Lake area monitoring, and provide many years of data query statistics, area and water level changes in contrast, image change contrast, Lakes region of dynamic change display and other functions to meet the needs of different users on the monitoring results. In addition, in 2011, "The Environmental Remote Sensing Dynamic Monitoring of geographic information systems in the Sanjiangyuan area".

(2) Disaster dynamic monitoring. Remote sensing technology throughout geological hazard survey, monitoring, early warning and assessment process. Conducting geological disaster monitoring and governance in the application of remote sensing technology has broad prospects [6].

2008 Wenchuan earthquake, Yushu in Qinghai Province earthquake in 2010, after the 2011 Yingjiang in Yunnan Province earthquake, mapping geographic information sector rapid access and integration of disaster latest image data, by contrast with the historical data to determine the affected range, area, roads, housing and other facilities the extent of damage, and the topography changes, disaster relief, disaster assessment and reconstruction to provide timely and accurate mapping and geographic information results.

In August 2010, Yunnan Nujiang Lisu Autonomous the tribute County sudden debris flows. Yunnan Provincial Bureau of Surveying and Mapping dispatched UAV aerial emergency squad, shooting 148,7 square kilometers, $0.3 \mathrm{~m}$ high-resolution image of timely, comprehensive, truly reflects the disaster [7].

(3) Urban change and construction management monitoring. In the special context of urbanization development, the need for urban change monitoring, timely grasp of urbanization on space, time changes, and development trends. Towns change monitoring the main task is to carry out monitoring of Residential land for construction of the pilot provinces for the country at the county level and above cities, towns below the county level, the main results of the "12th Five-stage goal is the formation of the corresponding data sets, and submit two monitoring reports and maps.

"Eleventh Five-Year" period, Chongqing consecutive years to carry out dynamic monitoring of the main city of
Chongqing urban construction land, find out the Chongqing urban construction and development characteristics, strong support for the assessment of overall urban and rural planning and implementation, planning and urban management. Chongqing main city of forest resources monitoring conducted annually for Chongqing Urban Planning Bureau to provide monitoring results, to grasp the changes of the city of forest resources. 2006 to carry out remote sensing monitoring of the waters of rivers and lakes. In 2008, use of high-resolution remote sensing image interpretation urban road network, urban transport development of the relevant government departments.

Meticulous management of the city, Beijing mapping geographic information sector with the relevant departments to take advantage of the "Beijing-1" satellite and airborne remote sensing technology to carry out the dynamic monitoring of the surface of rivers and lakes of the city water system and wetlands, water and soil erosion survey of forest resources survey and other work, accurate knowledge of the status quo and development trend of urban surface resources.

(4) Agriculture, forestry, water conservancy monitoring. Remote sensing technology has been widely used in the monitoring of agricultural production, and have achieved greater results in the identification of crop area estimates, growth monitoring, drought monitoring, disaster assessment and crop yield estimation. Mapping geographic information sector with the agricultural sector of the national wheat, corn, soybeans and other crops for yield estimation and growth monitoring. In the field of precision agriculture, remote sensing technology in farmland foundation status survey and guidance farmland irrigation, fertilization, pest control, weed control, harvesting made successful applications, it has become the primary means of access to spatial and temporal changes in precision agriculture farmland information[8].

Remote sensing technology can be applied in forestry investigation, dynamic monitoring, pest and disease investigation.

The use of remote sensing technology for situation monitoring, hydrological monitoring, engineering danger information, etc., can also be applied to flood disaster early warning, disaster assessment.

\section{EXISTENT PROBLEMS AND PROSPECTS}

\section{A. Existent Problems}

(1) The lack of ability to obtain remote sensing image data needs to be improved. The various types of remote sensing image data is indispensable to launch a nationwide geographic national conditions monitoring. At present, the basic realization of the resolution satellite image data in the 2000-2003 national coverage, high-resolution satellite image data for 2007-2010. Constitute a time series is difficult due to in nationwide considerable resolution images, remote sensing image data for a long time there were deficiencies in monitoring and analysis phase. In the case of lack of funds, there is no independent property right satellite, this situation is likely to continue for several years. Multi-source remote sensing image data acquisition is still dependent on foreign 
short-term satellite data, lack of domestic aviation, aerospace remote sensing data acquisition capabilities, periodically, the coverage of a wide variety of remote sensing data accessibility uncertainty.

In general, the current of remote sensing data acquisition capabilities can not meet the business needs of the geographic national conditions monitoring, the mapping satellite development strategy has been developed, full-service geographic national conditions monitoring data requirements also require a certain amount of time.

(2) The key technical issues to be resolved. To achieve a geographic national conditions monitoring, to solve the key technologies are as follows:

1) Multi-source data fusion and processing technology. How will these multi-source data fusion and processing is currently one of the difficulties. Geographic national conditions monitoring data in large quantities, types, remote sensing image data clusters distributed processing, real-time dynamic ground survey data processing, the thematic data space treatment technical means, to achieve fast and efficient processing of geographic national conditions monitoring data. Of GIS data, mapping geographic information sector monitoring data and other professional departments fusion, for example, water conservancy survey, ten use survey information, this information using the standard grid accuracy may be we may not How this information fusion processing, which is a problem.

2) Remote sensing information extraction and interpretation techniques. Geographic feature library and interpret knowledge database, build geographic national conditions monitoring information extracted the hierarchy typical natural geographic feature extraction and interpretation techniques, human geography elements to extract and interpret technical characteristics of the natural, human geography elements through multidimensional dynamic remote sensing data form, tense, texture and spatial relationships feature extraction and its optimized combination of methods to achieve network information extraction and interpretation of interpretation. Until now, still rely on outside industry to submit data back, within the industry, according to the image annotation we must demand to be able to do with a computer to automatically extract and interpret information. Abroad now has automatic extraction of water, roads, houses and other items through the computer. In addition, the need to achieve the semi-automation of human-computer interaction, automatic and semi-automatic information extraction and interpreted a technical difficulty.

3) Geographical elements of change detection technology. Geographic features change detection technology is the core technology of geographic national conditions monitoring. What is the geographic feature change detection, technical means of multi-source temporal remote sensing image contrast, high-resolution remote sensing images with existing basic geographic information data comparison, change contrast geographic features, to determine whether the geographic feature changes determine changes region, identification of changes in the category, the evaluation of changes in spatial and temporal distribution patterns, access to important geographic features and key areas of change, accurately reveal the changes in the spatial distribution and development law. Geographic national conditions and monitoring urgent need is how to be able to not the same phase of the data through the computer automatically analyzes the changes in the region and the corresponding information automatically find out and white dynamic prompts, the operating personnel according to the needs of these changes again technology means of extraction and analysis, which is a key technology that can reduce a lot of manual work.

(3) The lack of remote sensing technology and applications personnel. Geographic national conditions monitoring is a long-term and complex systems engineering, mapping geographic information sector accumulation of remote sensing technology also needed to be fleshed out, need technical training. Fully carry out large-scale geographic national conditions monitoring, require a large number of remote sensing technology personnel. The main task of the university is to train technical personnel. Wuhan University in 2012 geographic national conditions monitoring the professional start recruiting students, is the nation's first training of geographic national conditions and monitoring of technical expertise in the school. Develop remote sensing technology and applications personnel closest professional remote sensing science and technology, about 20 college enrollments, new set of professional basically the last ten years. The number of graduates and less technically can not fully meet the technology needs of geographic national conditions monitoring. Surveying Engineering, geographic information systems, and other related professional graduates in the number has reached a certain size, but a big gap between the level of applications of remote sensing technology.

\section{B. Prospects}

The next 5-10 years, geographic national conditions monitoring will become the main business of mapping geographic information sector. Remote sensing technology will be rapid development, mainly in the following three aspects:

(1) Access to remote sensing data capacity will improve. Currently, remote sensing image in many industries have been widely used, particularly in the high-resolution images, but most of the images are the products of foreign companies, spend a lot of money.

Mapping geographic information industry is developing rapidly in recent years, has developed a strategic plan for independent research and development satellite. "Resource-III mapping satellite" has been successfully launched, has already acquired a certain amount of image data," Tianditu" and has been applied to the system. Plans to launch subsequent operational satellites, the future will be the formation of a stable operational data acquisition capability.

SWDC (Siwei Digital Camera) series digital aerial photographic camera as space access to information and updated technical means to fill the gaps, state certification in 2007 and put into use. SWDC Series digital aerial 
photography instrument can be widely applied to the land, mapping, water conservancy, highway, railway, urban construction, environmental protection, tourism and other sectors, and has a broad market and application prospect. 2008 has been used in the production of national basic aerial photography. The SWDC possess fast data acquisition capabilities, access to the quake-hit areas, Beichuan, Pingwu County and Qingchuan counties aerial remote sensing images in 2008.

In summary, the three-dimensional multi-sensor airborne remote sensing system was gradually improved, professional remote sensing data, the rapid development of fast processing hardware and software. In addition, China plans to highresolution Earth observation system built after 2020. The future will achieve the empty earth integrated remote sensing image acquisition capability, can provide data protection for geographic national conditions monitoring.

(2) Increase research investment, to solve the technical problems of remote sensing applications. As a new, integrated, cross-geographic national conditions monitoring and the complexity of the subject system, need to have their own basic theories and key technologies, so as to geographic conditions survey, a comprehensive analysis of the application and decision-making support to promote geographical national conditions monitoring disciplines development.

Geographic national conditions and monitoring of the future in the field of research is more technical problems associated with remote sensing technology include: selected for geographic national conditions monitoring sensors the building empty earth integrated comprehensive monitoring network and monitoring system, can not meet the monitoring requirements sensor supplement; study the mechanism of surface imaging in different scales, the establishment of multiscale, multi-temporal, multi-source data change detection techniques. The high spatial and high temporal resolution geographic national conditions and dynamic change detection technology is an important research direction.

The national relevant departments have to pay attention to, and multisectoral research project. The directly oriented geographic national conditions monitoring, but also need to increase research investment, to solve the technical problems of remote sensing applications, to provide technical support to carry out a comprehensive geographic national conditions monitoring.

(3) Emphasis on Remote Sensing Applications, personnel training, and to provide protection to carry out geographic national conditions monitoring. During the "12th Five-Year" geographic national conditions monitoring in the pilot phase of Remote Sensing Applications, mainly through short-term technical training, the number of temporary need much talent. "Thirteen Five" will carry out a comprehensive the geography national conditions monitoring, mapping geographic information sector will be the main work will require a large number of remote sensing applications and technical personnel.
Very little is closely related to the number of college graduates and remote sensing, remote sensing application technology related professional students master limited capacity, can not fully meet the needs of the geographic national conditions monitoring of remote sensing technology talent. Therefore, from now on, the relevant departments should attach importance to the cultivation of Remote Sensing Applications, colleges and universities should be targeted to change the training objectives in order to adapt to the needs of the community, and to provide personnel protection to carry out a comprehensive geographic national conditions monitoring.

\section{CONCLUSION}

Geographic national conditions and monitoring work is still in its infancy, "Thirteen Five-Year" period will carry out a comprehensive geographic national conditions monitoring work. The remote sensing technology is an important part of the monitoring of the geographic national conditions, and in some areas has been initially applied. Meet to carry out a comprehensive geographic national conditions monitoring there are many problems to be solved, I believe around the remote sensing technology in the future, the problem will be gradually resolved, remote sensing technology will provide protection for geographical national conditions monitoring work.

\section{REFERENCES}

[1] Qin Zhang,Wenfeng Fan, "The Mapping and Geographical Condition Monitoring, " Bulletin of Surveying and Mapping,pp.78-80,November 2012.

[2] Deren Li,Haigang Sui,Jie Shan,"Discussion on Key Technologies of Geographic National Conditions Monitoring" Geomatics and Information Science of Wuhan University,Vol.37,pp.505-512,May 2012.

[3] Shuwen Wang,Junwei Liu,“Application and Research of Geographical Conditions Monitoring Based on Remote Sensing and GIS, "Bulletin of Surveying and Mapping,pp.51-54,August 2012.

[4] Chaofei Qiao,"Review of Overseas National Geographic Conditions Monitoring" Bulletin of Surveying and Mapping,pp.81-83, November 2011.

[5] Junyong Chen," Study Notes on Geographic National Conditions Monitoring," Acta Geodaetica et Cartographica Sinica,Vol.41,pp.633-635, October 2012.

[6] Huifen Xie,"The Application of Remote Sensing on Geological Disaster Monitoring and M anagement," Geomatics \& Spatial Information Technology,Vol.34,pp.242-243,June 2012.

[7] Publicity Center of Surveying and Mapping in China. Research and Probing of Geographic National Conditions Monitoring.Beijing: Surveying and Mapping Press,2011.

[8] Jihua Meng, Bingfang Wu, Xin Du, “A Review and Outlook of Applying Remote Sensing to Precision Agriculture," Remote Sensing for Land \& Resources,pp.1-7, September 2011 